\title{
O"demo" rosiano - entre a poesia popular e o romantismo alemão
}

\author{
Rosa's "Demons" - Navigating between Brazilian \\ Popular Poetry and German Romanticism
}

Kathrin H. Rosenfield

Universidade Federal do Rio Grande do Sul

Resumo: Esse artigo trata das múltiplas inspirações temáticas, estilísticas e atmosféricas que chegam a uma perfeita fusão poética em Grande Sertão: Veredas. Rosa concilia as lições do Kunstmärchen (conto popular artístico do século XIX alemão) com as tradições da poesia popular brasileira.

Palavras-chave: Guimarães Rosa. Demônio. Poesia popular. Kunstmärchen.

Abstract: This article investigates the multiple thematic, stylistic and atmospheric influences, sources and inspirational materials that result in a perfect poetic blend in Guimarães Rosa's Grande Sertão: Veredas. Rosa combines the lessons coming from the Kunstmärchen (german folktale tradition) with Brazilian popular poetry.

Keywords: Guimarães Rosa. Demon. Devil. Popular poetry. Kunstmärchen. 


\section{A reconquista da ingenuidade}

J. G. Rosa é o mais poético, popular e erudito dos autores brasileiros. Seu romance Grande Sertão: Veredas é quase um poema ou uma lenda com intensidade espiritual e emocional - uma constante inspiração para artistas que têm a sensibilidade pela poesia popular brasileira. É difícil traduzir nas palavras de outros idiomas a graça da literatura oral que J.G. Rosa soube captar na sua adaptação modernista-tardia, mas as gravuras ilustrando o viés popular e sertanejo da obra rosiana têm um apelo imediatamente universal - pensemos apenas em Poty ou nas obras da

Kathrin $\mathrm{H}$. Rosenfield austro-brasileira Maria Tomaselli.

O legado aparentemente "regional" é sertanejo e popular apenas numa face da moeda. Basta olhá-la de outro ângulo e essa mesma obra revela uma densidade que une o popular com inúmeras camadas eruditas e referências intertextuais que abrangem diversas tradições universais. Rosa atribuía máximo valor a essa dimensão metafísica que navega no simpático idioma popular brasileiro. Para ele, os sertanejos eram os maiores mestres da meditação - quase uns iogues natos -, por isso, era tão fácil passar da dicção dos sertanejos para os grandes "livros sagrados" da tradição indo-europeia. A "religião" poética de Rosa procurou "beber água de todos os rios", abraçando de modo fraterno o que há de melhor em todas as crenças e todos os imaginários. Aberta e acolhedora como uma fé cósmica, essa "metafísica" não só tem grande afinidade com a delicadeza de poetas como Hölderlin e Rilke, Kafka ou Musil que Rosa admirava; ela também abrange as artes da peleja e os ardis dos repentistas, trazendo à tona a poesia e a profundidade do pensamento de pessoas até então considerados como rústicos insignificantes. Rosa reforça um novo modo de percepção iniciado por Euclides da Cunha, cujo ensaio Os Sertões entoou o louvor das criaturas miúdas, entretanto, na obra rosiana, esse contato com o fundo oral, com as expressões populares que o Brasil litorâneo e metropolitano desconhecia, atinge um grau de diferenciação e riqueza nunca antes visto. Apenas nas últimas décadas os dicionários especializados do idioma rosiano (de Nilce Sant'Anna Martins ou de Luiz Coronel) nos sensibilizaram pelo fato de que os aparentes neologismos rosianos são, na verdade, muitas vezes apenas ativações de termos disponíveis e em uso no linguajar popular do sertão. E com essa linguagem redescoberta, Rosa abre também o acesso a uma afetividade peculiar, que oscila de modo inquietante entre a bondade criatural e a maldade assombrosa da existência humana: “viver é perigoso”, pondera Riobal- 
do. A aspiração ao "absoluto" e ao sagrado na obra rosiana é o antídoto à consciência avassaladora da maldade - o demo que espera na "matéria vertente" do homem humano. Rosa compartilhou a generosa aspiração "metafísica" ou "religiosa" com seus familiares e amigos sertanejos e, também, com sua esposa Aracy Moebius, a quem dedicou e legou sua obra, homenageando não apenas a grande amada, mas também o grande ser humano: foi Aracy quem ignorou as diretrizes discriminatórias do Itamaraty e pôs em risco sua carreira para salvar a vida de muitos judeus aos quais o consulado de Hamburgo teria negado o visto, não tivesse ela burlado as ordens do governo getulista.

Minha experiência pessoal com Rosa é reveladora da perfeita fusão que o autor atingiu entre o popular e o erudito. Quando li Grande Sertão: Veredas pela primeira vez, nada sabia do Brasil, de sua rica tradiO "demo" rosiano ção popular, nem conhecia muito bem o português. Mesmo assim, fiquei impressionada com a transformação moderna das narrativas medievais que, por sua vez, souberam desvincular-se da literatura escrita em latim graças ao acolhimento das tradições míticas e orais locais ${ }^{1}$. O mesmo princípio prevalece na obra rosiana, que funde confunde e o princípio romanesco moderno com o das práticas narrativas daquelas lendas e epopeias muito antigas, medievais, que as tradições sertanejas conservaram como formas simples - graças ao contínuo trabalho dos poetas populares, que tecem suas evoluções em torno desse fundo.

o que mais me impressionou nas sucessivas releituras era o dom de inocular nesse fundo popular - que é anacrônico e "atrasado" apenas em aparência - todo um potencial filosófico complexo, com insights psicológicos contemplativos e modernos. Sem saber nada do autor como vice-cônsul em Hamburgo, nem de sua segunda esposa, senti-me, desde a primeira leitura, pessoalmente tocada pelas ruminações de Riobaldo em torno da "matéria vertente". As dúvidas a respeito do fundo daimônico do homem a exploração do próprio passado comprometido pelo deslize para as atrocidades da jagunçagem, a tortura de Riobaldo, tentando passar a limpo o que exatamente aconteceu, e descobrindo que tomou parte em atrocidades sem sentido... Tudo isso tinha imensa afinidade com as inquietudes da minha geração de austríacos e alemães, que começaram a elaborar a culpa coletiva recalcada após o holocausto

1 Cf. a respeito desse assunto meus livros K. Rosenfield, Os Descaminhos do Demo (Imago-Edusp, 1992) e Desenveredando Rosa (Topbooks, 2006) 
nazista. A arte de G. Rosa, de fato deu uma dimensão universal às coisas sertanejas: o sertão não está apenas no planalto brasileiro, o sertão é o mundo - metáfora das coisas mais maravilhosas e terríveis que a imaginação humana é capaz de produzir.

A história de Riobaldo gira em torno dos muitos nomes do demo e de seus modos sorrateiros de possuir pessoas aparentemente inofensivas. A figura popular do demônio permitiu abordar não só o imaginário popular local, mas o mal metafísico que aparece ora na forma de Lúcifer, ora na de Mefistófeles ou de Fausto - entre tantas outras metáforas Kathrin $H$. da sedução, da perversão e de outros deslizes para a atrocidade - em Rosenfield voga na literatura europeia do início do século XX. O Fausto de Goethe estava particularmente ancorado na memória coletiva, de forma que Thomas Mann e G. Rosa podiam retomá-lo, adaptando-o aos mais diversos contextos (religioso e político, artístico e existencial). É típica do gênio rosiano a leveza da adaptação dos motivos clássicos ao estilo da dicção popular. Com rápidos toques ele transforma por completo as formas consagradas, que ficam como um simples timbre, como um perfume - perfeitamente dissolvidos na matéria brasileira e sertaneja que Rosa escolheu. Pensemos no drama do Fausto iluminista de Goethe, com sua desmedida vontade de saber que o leva ao pacto, arrastando-o para as luxúrias subsequentes - a volúpia de gozar dos conhecimentos na vida, a sedução de Gretchen, até a redenção pelo amor da amada defunta; ou no Fausto de Mann, que elabora mais a atração demoníaca da criatividade desmedida (pendor esse que G. Rosa conhecia pessoalmente muito bem). Tudo isso encontramos em Rosa - porém em radical metamorfose: como recortes de um caleidoscópio refratando os elementos da tradição clássica pelas lentes e os espelhos do sertão: colcha de retalhos cerzida pelas reminiscências do narrador Riobaldo, que é ao mesmo tempo jagunço e filho de latifundiário, herdeiro de Selorico Mendes e filho da mãe solteira (e provavelmente índia) Bigrí.

A figura da ambiguidade demoníaca é invocada a todo momento. Logo nas primeiras páginas, Riobaldo afirma que o diabo surge às brutas e que Deus é traiçoeiro. Em outro momento, diz que Deus existe mesmo quando não há, mas o diabo não precisa existir para haver. Esse deslize permanente entre o bem e o mal que assim perdem a referência firme e dissolvem-se em ambiguidades incertas não caracteriza apenas Diadorim, mas termina por afetar todas as figuras e afirmações. Rosa parte do senso comum, da linguagem popular brasileira que emerge das dicoto- 
mias cristãs e do imaginário que dois mil anos de doutrina e catequese legaram a um país católico como o Brasil - a oposição do Bem e do Mal, de Deus (com D maiúscula) e do demo (como mal relativo). Mas essa dicotomia cede o lugar ao sincretismo brasileiro que dissolveu as referências doutrinárias. A religiosidade brasileira não trata bem das categorias cristãs - ela "bebe água de todos os rios", como diz Riobaldo. Alimenta-se dos mitos indígenas e africanos, indo-europeus, gregos e romanos. Assim, Rosa pratica uma espécie de paganismo cristão (como, aliás, seu grande modelo Goethe), mergulha fundo nas formas de representação indígenas, pagãs e politeístas que jamais trabalham com oposições binárias rígidas, mas com rede e teias de tensões que conectam divindades e daimones (forças do cosmos) em trocas multipolares. Impossível pensar nesse universo (rosiano e politeísta) que o espírito seria bom e a carne má. Cada força, O "demo" rosiano cada elemento representado por uma divindade ou daimon é boa e má, tudo depende do equilíbrio, das trocas (harmoniosas ou conflitivas). Nem mesmo a morte é má, mas tem que ser vista como dissolução necessária no equilíbrio de um cosmos animado por muita forças. - Voltando a GSV, as dúvidas de Riobaldo quanto à existência de Deus e do demo vêm, principalmente, dessa incompatibilidade entre o imaginário intuitivo popular (que na verdade pensa quase sempre de modo "pagão" e politeísta - e mais ainda no Brasil), de um lado; de outro, o vocabulário duro, dicotômico da nossa tradição cristã. Na minha visão, ao lado dos muitos nomes do demo que encontramos em GSV, temos também muitos nomes para Deus: alegria, beleza, amor - que aparecem nesse romance nas formas mais ricas e belas. Pensemos, por exemplo, em Nhorinhã, a Afrodite do sertão; ou em Hortênsia e Maria da Luz: elas refletem os encantos sensuais e sagrados de deusas como Anahita ou da nossa Pomba Gira, doadoras de plenitude carnal e da prosperidade material. Essas promessas divinas do sincretismo brasileiro vão muito além do exclusivismo mesquinho do ideal da virgem Maria ou do casamento monogâmico cristãos. Nas imagens ambivalentes da beleza e da força de Diadorim, reflete-se algo divino suspenso entre o bem e o mal. É Diadorim quem abre os olhos de Riobaldo para as belezas e as delicadezas do mundo, embora Diadorim seja também um alter ego do Hermógenes, da ira e do ressentimento destruidor. Diadorim é a referência confiável, mas ele não deixa de ser "traiçoeiro" como todos os deuses pagãos - não em absoluto, apenas na medida em que os seres humanos depositam uma fé ilusória na estabilidade de suas próprias ilusões, nos fantasmas que se inventam e projetam sobre as figuras divinas. 
A lei dos jagunços é a da luta pela sobrevivência de seres que nasceram do caos: eles representam a humanidade no estado puro. Riobaldo é um jagunço diferente porque foi despertado - primeiro pela bondade da mãe Bigrí, depois pelo "menino" que o levou para a travessia do Rio São Francisco (o episódio evoca o encontro de Parsifal com os cavalheiros da corte do Rei Arthur). Todo esse ciclo de fantasmas da beleza e da força retorna e se realiza no reencontro com a figura Reinaldo-Diadorim. As travessias que Riobaldo busca sob o impacto das reminiscências da sua primeira aventura com o "menino" são uma verKathrin $H$. dadeira "educação sentimental" brasileira. O romance, os contos e as Rosenfield novelas rosianas traduzem em idioma popular a busca de formação ética e estética do Bildungsroman europeu, um programa narrativo à procura do amadurecimento moral e sentimental do indivíduo perdido nas grandes transformações sociais e políticas de seu meio.

\section{As meditações filosóficas em linguagem sertaneja}

Rosa é, em primeiro lugar, o magistral tradutor entre imaginários culturalmente investidos. Quem antes dele teria pensado em uma afinidade entre a delicadeza da poesia romântica alemã e a rudeza do sertão? Precisamos de Rosa para perceber os potenciais mágicos - a irradiação fascinante-e-angustiosa que o sertão ganhou, graças à inovação rosiana. São as estórias rosianas que revelaram os elos dos sertões com as tonalidades emocionais das lendas e dos contos de fada, Märchen. Retrospectivamente, isso parece uma adaptação simples: bastou soltar-se da abordagem racional e do estilo de historiador romano que prevalece na obra de Euclides, mas que na época de Rosa, esse soltar-se era o grande feito! Onde Euclides procurava inscrever o Sertão e o Brasil num sistema de mediações históricas e sociais hegelianas, Rosa confia na universalidade da poesia popular para universalizar a aparente particularidade irredutível: o sertão é a imagem do mundo, o jagunço a figura da condição humana pós 1945.

Com inédita desenvoltura, a "oralidade" rosiana absorve os requintes do Kunstmärchen, a profundidade psicológica e a inquietante estranheza que conferem à doçura ingênua o frêmito da sorrateira ameaça. Diadorim - mas não só ele - são as figuras emblemáticas deste romantismo modernista que traduz em oralidade sertaneja os achados poéticos mais preciosos de tradições formais alienígenas e de épocas que pareciam revolvidas. Como os mestres do conto inquietante-e- 
-estranho, Rosa nos introduz nos precipícios vertiginosos do traiçoeiro idilo sertanejo. Os riachos, as plantas e os pássaros que evocam o aconchego uterino no "sertãozinho" ameno recebem, inopinadamente, uma aura angustiosa - ambivalência paradoxal que convida a refletir. Por mais que seja ameno o: "sertãozinho de minha terra, baixo da ponta da Serra das Maravilhas, entre a Serra dos Alegres e o Sítio do Caramujo, trás das fontes do Verde, do verde que verte no Paracatu" (ROSA, 1976, p. 35) - "para trás, não há paz", adverte o narrador. Deste modo, o Diadorim das constantes rememorações surge sempre como um híbrido angelical-e-demoníaco. Desde o primeiro encontro com o "menino", o narrado parece estar suspenso no redemoinho de encantos e pavores. A presença de Diadorim é um "lusfus" de brilhos lunares (ROSA, 1976, p. 25); "sombra de sombra, fuscava" (ROSA, 1976, p. 316) olhos verdes

O "demo" rosiano crescendo como o mar "cresciam sem beira, dum verde dos outros verdes... minha Nossa Senhora da Abadia" (ROSA, 1976, p. 374).

O equilíbrio precário entre doçura e inquietação, candura e assombro é um dos segredos do fascínio que Rosa exerce sobre seus leitores. Apesar da intensa cor local sertaneja, esse traço lembra as novelas dos românticos alemães. Sobretudo, para quem conhece as reflexões de Kierkegaard à respeito das narrativas de Tieck - o romântico que elevou o Märchen a um gênero artístico ímpar. Em 1841, o filósofo descreve o efeito da aura atmosférica inquietante que envolve as figuras de Tieck:

Tieck tem um dom peculiar de nos inocular sentimentos esquizitos e maravilhosos, e as figuras humanas idealizadas que ficam visíveis nos inspiram, devido às suas esquisitices, uma verdadeira angústia, pois eles se parecem às vezes com os mais insólitos produtos naturais, e seus olhos fieis e sagazes não nos transmitem tanta confiança mas antes uma angústia estranha e inquietante (KIERKEGAARD, 1976, p. 301).

Não é exatamente esse sentimento que nos assalta às vezes quando seguimos as divagações riobaldianas, seu tom familiar elevado ao derradeiro grau de esquisitice? Nos anos 1930 e 40, quando Rosa começa a escrever, o sertão é suficientemente (des)conhecido para absorver bem as atmosferas e tonalidades ambíguas (Stimmungen) que conferem à realidade uma aura enigmática - um clima que se presta para transfigurações imaginárias. Trabalhando na direção oposta do realismo 
de Graciliano, Rosa reconduz o real para o topos poético: transfigura o espaço real numa afinação musical ou vibração "existencial" - Gestimmtsein diria Heidegger em Ser e Tempo (1979, p. 134). Essa disposição-afinação é um estado ôntico mais que emocional (Befindlichkeit), um estar-no-mundo familiar e cotidiano, mas revela o ser-estar-aí (Dasein) em seu ser-lançado (HEIDEGGER, 1979, p. 136.) e, assim, o familiar tende a bascular na inquietante estranheza. É justamente esse movimento de báscula que intriga e inquieta Riobaldo.

A história desta intensidade atmosférica da Gestimmtheit começa

Kathrin $\mathrm{H}$. mais de um século antes de Heidegger - com o topos da Waldeinsamkeit Rosenfield romântica: a natureza aberta - acolhedora e inquietante-estranha (un) heimlich - é o lugar (real-irreal) no qual o tempo, o espaço e o indivíduo se dissolvem e fusionam. $O$ alvo Reinaldo-Diadorim pertence, na sua ambivalência maravilhosa-e-inquietante, ao universo romântico de figuras como Der blonde Eckbert, O Alvo Egberto de Tieck (TIECK, 1796, passim) ou aos "lusco-fuscos" do Zwielicht de Eichendorff (EICHENDORFF, 1815, passim). Esses temas do fantástico maravilhoso dos contos de fada já perderam sua ingenuidade e entraram no vórtice das ambivalências atmosféricas (Stimmung) durante o romantismo. A oscilação pura entre pavor e maravilhamento é o cerne da lírica narrativa romântica, e continua a exercer seu fascínio sobre poetas e narradores da modernidade - pensemos apenas nas atmosferas carregadas em Benn e Trakl, Rilke, Kafka e Musil. A modernidade compartilha o afã pelas imagens que conferem sensação-e-sentido no instante do apanhado das metáforas altamente ambíguas e densas - relâmpagos de entre-entendimento ou des-entendimento que se situam bem antes da compreensão consciente, escapando também ao esforço analítico da cognição.

É esse fato que torna tão fascinantes e prazerosas a fanopeia e a melopeia praticadas por Rosa, pois são flagrantes as semelhanças entre o frêmito inquietante dos românticos e as atmosferas que envolvem o enigmático amor por Diadorim, que intriga Riobaldo ainda muitos anos depois da morte deste amigo que se des-e-re-encanta no nome de Deodorina. O pesar, misto de culpa, de angústia suspensa e melancolia doce-amarga está presente desde o início da narrativa. Suas causas permanecem insondáveis, porém, permeiam todas as lembranças e cristalizam-se ora em um motivo, ora em outro. Por exemplo, em torno de uma canção - a canção de Siruiz: 


\begin{abstract}
Dava o raiar, entreluz da aurora, quando o céu branquece. ... e o que é, é saudade .... Um falou mais alto, aquilo era bonito e sem tino: - 'Siruiz, cadê a moça virgem?' Largamos a estrada, no capim molhado meus pés se lavavam. Algum, aquele Siruiz, cantou, palavras diversas, para mim a toada toda estranha: ... vinham quebrando as barras. Dia de maio, com orvalho, eu disse. Lembrança da gente é assim (ROSA, 1976, p. 93).
\end{abstract}

O sertanejo-jagunço deixa de ser uma figura regionalista. Torna-se a imagem do micro/macro-cosmos, do tudo-nada, da travessia, do amor carnal-e-místico (cântico), físico-metafísico. Rosa dá ao "sertanejo" todos os acentos da vida contemplativa oriental e ocidental, entretecendo os motivos das travessias iniciáticas do Oriente com as do OcidenO "demo" rosiano te $^{2}$. Além disso, a entrevista com Lorenz toca com insistência irônica na analogia críptica que aproxima a "brasilidade", a vida do "sertanejo" e o "sertão" do ideal romântico do isolamento introvertido do trabalho poético: o narrador é concebido como réplica do personagem e a trajetória da narração (travessia poética da linguagem) reitera a da experiência narrada no espaço geográfico.

Como no mundo maravilhoso dos românticos, Riobaldo também é um heroi que se perde em metáforas e se dissolve em atmosfera - em particular, na atmosfera maravilhosa-angustiosa-melancólica. Kierkegaard foi o primeiro a analisar o tipo "riobaldiano" de medo que não tem objeto. o filósofo baseou sua filosofia da angústia no medo inominável dos românticos (Tieck em particular) que criaram a atmosfera do medo de algo que é nada. Kierkegaard a vê como uma capacidade espiritual próxima do pesar melancólico. Nos Escritos filosófico-teológicos, o filósofo comenta o "salto qualitativo" - isto é, o enigmático irromper repentino - que faz a transição entre o maravilhoso e o inquietante (heimlich-unheimlich), salto este no qual o medo aparece como uma força alheia que toma conta do sujeito (KIERKEGAARD, 1961, p. 488 s., 473 e 601) ${ }^{3}$. Kierkegard concebe a

\footnotetext{
2 Pensemos no Vanaprastha (monge da floresta indiano) ou no Parzival de Wolfram Von Eschenbach; ou ainda no Simplizissimus de Grimmelshausen, 1668.

3 Karl Heinz Bohrer comenta essa dimensão atmosférica que Kierkegaard aborda nos seus Philosophisch Theologische Schriften. Cf. BOHRER, Karl Heinz. Grenzen des Aesthetischen, Hanser 1997, p. 47 s.. A atmosfera do estar-perdido que ele tem em mente vem de uma ilustração do terceiro volume do Des KnabenWunderhorn editado por Achim Von Arnim e Clemens Brentano: um homem e uma mulher em vestimenta medieval, cada um tocando sua harpa e alaúde, juntos mas separados pela profunda compenetração com o instrumento, perseguindo algo inefável.
} 
Stimmung como um estado no qual as mediações entre o sujeito pensante e o objeto pensado são dissolvidas. Em outras palavras, a continuidade potencial da forma de experiência (consciência, trabalho do conceito).

Kathrin $H$. dissolve-se para a consciência estética na própria presença (präsentischauflöst); [...]

Pertence a imediatez do estético a intensidade do momento; esta, incapaz de um auto-esclarecimento do ético, é sujeita ao modo do pesar melancólico (Schwermut), ao qual Kierkegaard atribui a Rosenfield conotação do "inexplicável” e do "infinito" (BOHRER, p. 163-4).

A própria intensidade epifânica produz seu anticlímax melancólico, a imagem poética repete a experiência vivida da perda. Por isso, Rosa-poeta pode diretamente identificar-se com os sertanejos das suas estórias e ao mesmo tempo insistir no trabalho "mediúnico", intuitivo, de sua composição: ambas travessias (a poética e a vivida) correspondem à dissolução do indivíduo, do tempo e do espaço. A aventura de Riobaldo (personagem-narrador) não é mais propriamente um relato de uma cadeia de acontecimentos objetivos, mas uma objetivação de estados e atmosferas difíceis de localizar, na medida em que flutuam entre o dentro e o fora, o subjetivo e o objetivo.

\section{As inspirações populares e eruditas da obra rosiana}

Para atingir essa fusão intuitiva-e-intelectual, Grande Sertão: Veredas lança mão de técnicas narrativas tradicionais e vanguardistas, além de mesclar elementos de línguas estrangeiras e estilos totalmente estranhos às convenções brasileiras do início do século XX com as falas orais e escritas mais arraigadamente brasileiras. Assim, o romance de G. Rosa traduz para a sensibilidade contemporânea uma visão unzeitgemäss - fora do tempo e ultrapassada: a concepção dos "idealistas" e o idioma dos "metafísicos" que ainda reina no sertão ingênuo - dentro e fora da gente. Essa tradução pressupõe uma confiança profunda na capacidade da linguagem poética, razão pela qual Rosa sempre sublinhou a profunda "religiosidade" de sua obra, na qual as esperanças escatológicas e redentoras lembram antes Dostoïevski e Kafka do que Joyce: "Escrevo para me aproximar de Deus", afirma o autor, reforçando o cunho redentor e a referência metafísica da sua escritura com observações como esta: "Eu, quando escrevo [...] vou fazendo como se o estivesse 'traduzindo' de um alto original, existente alhures, no mundo astral ou no 'plano das ideias', dos arquétipos” (ROSA, 1981, p. 63-64). 
Não se pode esquecer, portanto, que Rosa defende sempre sua visão transcendente da arte e concebe o sertão como o lugar onde há somente lendas e contos exemplares. $O$ ingênuo herói rosiano dissolve "pretensões intelectualizantes" e "cerebrais". A reflexão sobre a condição humana - a indeterminação do Eu freudiano, o sujeito anti-metafísico e descentrado de Heidegger, e muitos outros motes que estão no ar - não são diretamente abordados. Aparecem traduzidos no idioma intuitivo que fala para a sensibilidade brasileira, na chave popular dos casos dos contadores, nas metáforas dos deslizes incessantes da "matéria vertente", nas imagens do sertão como magma sem forma que "está dentro da gente."

O "demo"

O que Rosa não conseguiu atingir com sua primeira poesia morosiano dernista, ele o consegue com as estórias e o romance. De Magma a Sagarana, Rosa supera a rigidez da sua fase inicial e consegue traduzir num idioma único - rosiano - o charme singular da poesia popular brasileira. Magma, embora tenha marcado a estreia do escritor com uma relevante premiação, não satisfez as exigências do próprio autor, que terminou por proibir a reedição desta coletânea poética. Vejamos apenas um dos poemas que procuram recuperar a doce intensidade das imagens populares. O que acontece, no entanto, é uma imposição de reflexões que não surgem naturalmente das evocações concretas, prejudicando o modelo tradicional:

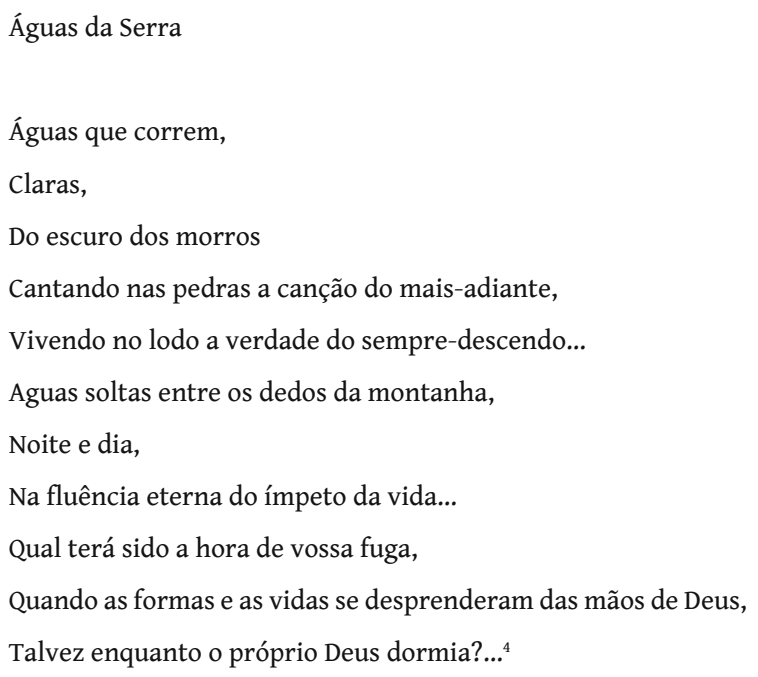

4 CASCUDO, Luís da Câmara. Vaqueiros e Cantadores, São Paulo, Itatiaia, 1984, p. 93. 
Rosa apoia-se nos princípios formais e nos motivos da poesia popular. No primeiro e no terceiro versos, o ritmo é o da parcela (10 versos de 4-5 sílabas), o motivo é semelhante da parcela (por exemplo, da peleja entre José Francalino e Cego Aderaldo), mas Rosa varia, dando-se as liberdades de modulação do verso livre. Além disto, ele modula também a tonalidade emocional introduzindo noções mais abstratas que convidam à reflexão; se o motivo é o mesmo, se o desejo de contemplação sensível do movimento da natureza tira proveito dos ritmos populares, Rosa não se contenta na observação ingênua e puramente sensível. Ele a vincula com Kathrin $\mathrm{H}$. elementos como "a canção do mais-adiante" ou "a verdade do sempreRosenfield descendo" ou a "fluência eterna do ímpeto da vida", cuja presença num poema inicialmente "ingênuo" faz o leitor percorrer rápido demais o caminho - aliás nem sempre provável - que leva da sensação estética a um conceito abstrato e pobre (fluxo, vir a ser no desaparecer, eterno retorno, infinito...). A tentativa de unir a sensação plena do movimento das águas com o conceito de sempre-fluência heraclitiana é um grande fracasso pelo menos feita deste modo. 0 que fica claro é que Guimarães Rosa está constantemente hesitando entre o encanto da poesia ingênua e o prestígio do conceito e da abstração. Essa colagem fracassa porque perdem-se os encantos da poesia ingênua, sem, contudo, ganharem-se os prestígios de um trabalho de reflexão filosófica realmente rigorosa. Mais interessante ainda é que Guimarães Rosa busca mascarar muitas vezes o aporte conceitual com termos, por assim dizer, mais naturais. "Mais adiante" é um termo que propositalmente foi usado para substituir "devir" ou "vir a ser", mas que, afora pela sua novidade interessante, igualmente impede uma apreensão direta do objeto. Acredito que boa parte da obra de Guimarães faz o caminho do conceito abstrato para a construção estética das sensações através da narração de cenas, etc., é bem verdade, também, que esse viés "invertido" foi sendo substituído por um apagamento contínuo do conceito e uma imersão cada vez maior na imagem: mas o processo de criação nunca esteve livre destas noções - mesmo quando elas se desfaziam na difusão do desenvolvimento textual.

Substitui-se a emoção pura pela natureza - sem nenhuma mediação artificial do conceito - por essa curiosa emoção que sentimos quando, por um encadeamento analógico e sensível, conseguimos relacionar uma instância abstrata do pensamento com aquelas imagens que, antigamente, na nossa própria história pessoal "ingênua", geravam certos sentimentos profundos. 
Apenas nas narrativas posteriores Rosa encontra o espírito da improvisação popular: a modulação que entretece a peleja/desafio com a canção lírica. Assim, surge a tensão idílica-inquietante que confere a sua narrativa romanesca a aura do Märchen e o lirismo encantador e angustiante. Suas qualidades manifestam-se no instante: algo - um nada ou quase-nada - toca e abala de modo tangível, mimetizando o ser-assim das coisas elas mesmas. Fruto da perícia instantânea do poeta que assume subitamente, no meio de uma peleja, o tom reflexivo, a poesia popular já traz em si a tensão do não dito - o enigma de um repentino salto qualitativo que muda de tom, atmosfera, aura e disposição. Encerremos essa breve reflexão com os versos de José Francalino, na qual impressiona a oscilação entre o idilo (1-4) e seus avessos obscuros (v. 10) - o motivo da matéria vertente, inopinadamente revelado pelo "desvio" e a "procura":

O "demo"

rosiano

\author{
Balanço e navio \\ Navio e balanço, \\ Água e remanso \\ Na margem do rio \\ Procura o desvio \\ O desvio procura \\ Carreira segura \\ Segura carreira \\ Molhando a barreira \\ Das águas escuras. ${ }^{5}$
}

Num comentário sutil, Lawrence Flores Pereira (2006) escreveu a respeito de Francalino:

5 Cf. Cascudo, Luís da Câmara. Vaqueiros e Cantadores, São Paulo, Itatiaia, 1984, p. 87. 
que parece emanar desse poema, uma graça especial: o navio que balança, que busca sua passagem, que molha a barreira e que encontra finalmente seu caminho nas "águas escuras”. É um noturno que, embora jamais se desprenda da imagem concreta para assinalar um significado subjetivo, evidentemente sugere algo mais do que esses elementos extremamente concretos. Poderia chamar isso de monotonia tranquila, contemplação silenciosa, mas nada dá a ideia própria da sensação.

Kathrin $H$. Rosenfield

É a arte dessas sutis sugestões, das evocações de ideias que estão no limiar da consciência, mas não adquirem o peso da reflexão discursiva consciente, que caracteriza a poesia "popular" rosiana. Ela transcende o popular trivial, tornando-se filosófica, metafísica e universal para quem compartilhar o gosto meditativo do sertanejo idealizado pelo autor J. G. Rosa.

\section{REFERÊNCIAS}

BOHRER, Karl Heinz. Grenzen des Aesthetischen. Munich e Viena: Hanser, 1997.

CÂMARA CASCUDO, Luís da. Vaqueiros e Cantadores. São Paulo: Itatiaia, 1984.

EICHENDORFF, Joseph von: Zwielicht. 1815. Disponível em: http:// gutenberg.spiegel.de/buch/joseph-von-eichendorff-gedichte-4294/105. Acesso 26 de novembro de 2016.

ESCHENBACH, Wolfram Von. Parzival. Disponível em: http://gutenberg. spiegel.de/autor/wolfram-von-eschenbach-151.

GRIMMELSHAUSEN. Simplizissimus 1668. Disponível em : $h t t p: / / g u-$ tenberg.spiegel.de/buch/simplicius-simplicissimus-5248/1.

HEIDEGGER, Martin. Sein und Zeit. Niemeyer: Tübingen, 1979.

KIERKEGAARD. Über den Begriff der Ironie. Frankfurt a. Main: Suhrkamp, 1976. 
. Philosophisch Theologische Schriften. Köln / Olten: Jakob Hegner, 1961.

PEREIRA, L. F. Em busca de Canhotinho: estudo sobre um estado de exceção lírica e de errância na poesia popular nordestina. Nonada Letras em Revista, v. 2, n. 13, 2010, p. 47-61.

Pereira, Lawrence Flores. 2006, manuscrito inédito.

TIECK, Ludwig: Der BlondeEckbert. 1769. Disponível em: Projeto Gutenberg: http://gutenberg.spiegel.de/buch/der-blonde-eckbert-5492/1. Acesso 26 de novembro de 2016.

ROSA, João Guimarães: Grande Sertão: Veredas. Rio de Janeiro: José Olympio, 1976.

Correspondência com o tradutor italiano Eduardo Bizzarri. São Paulo: T. A. Queiroz, 1981.

- Recebido em julho / 2017

- Aceite em agosto / 2017 
